\title{
Raman and Surface-Enhanced Raman Scattering for Biofilm Characterization
}

\author{
Seda Keleştemur, Ertug Avci and Mustafa Çulha * \\ Department of Genetics and Bioengineering, Yeditepe University, Istanbul 34755, Turkey; \\ demirseda85@gmail.com (S.K.); ertugavci@gmail.com (E.A.) \\ * Correspondence: mculha@yeditepe.edu.tr; Tel.: +90-216-578-1587
}

Received: 7 December 2017; Accepted: 16 January 2018; Published: 19 January 2018

\begin{abstract}
Biofilms are a communal way of living for microorganisms in which microorganism cells are surrounded by extracellular polymeric substances (EPS). Most microorganisms can live in biofilm form. Since microorganisms are everywhere, understanding biofilm structure and composition is crucial for making the world a better place to live, not only for humans but also for other living creatures. Raman spectroscopy is a nondestructive technique and provides fingerprint information about an analyte of interest. Surface-enhanced Raman spectroscopy is a form of this technique and provides enhanced scattering of the analyte that is in close vicinity of a nanostructured noble metal surface such as silver or gold. In this review, the applications of both techniques and their combination with other biofilm analysis techniques for characterization of composition and structure of biofilms are discussed.
\end{abstract}

Keywords: Raman spectroscopy; surface-enhanced Raman spectroscopy; bacteria; biofilm; nanoparticles

\section{Introduction}

A biofilm is an assembly of microbial cells and extracellular polymeric substances (EPS) that are formed from polysaccharides, lipids, proteins, genetic materials, and humic-like substances [1]. EPS provides microorganisms irreversible attachment onto a surface and protects them from environmental stress conditions [2]. Microcolonies bury in an EPS matrix in a biofilm composition, which is surrounded by water channels. Water channels provide an exchange of nutrients and metabolites between the microorganisms and the aqueous phase [1,3]. The composition of the EPS also changes depending on the nature of the microorganism. In Gram-negative bacteria, the EPS consists of neutral and polyanionic polysaccharides, while in Gram-positive bacteria the EPS formation is cationic. On the other hand, the environmental conditions such as $\mathrm{pH}$, temperature, oxygen, and nitrogen levels, and also the surface properties, affect the composition of a biofilm $[3,4]$.

Identification of biofilm composition is very important for clarifying the interactions between the environment and microbial growth and also for understanding the molecular dynamics of the biofilm's own chaotic system. Biofilm analysis can be performed with microscopic, spectroscopic, and molecular techniques [5]. Improvements in analytical techniques have greatly contributed towards elucidating the structure of biofilms.

Microscopy was one of the pioneering techniques used to analyze biofilm structure. Confocal laser scanning microscopy (CLSM) provides an opportunity to monitor biofilm structure and dynamics during the accumulation stage [6]. Characterization of the three-dimensional architecture of biofilm composition is possible by using specific fluorescent dyes [7]. The combination of microscopy techniques allows detailed information to be obtained, as demonstrated in a study by Strathmann et al. [8] who combined epifluorescence microscopy with CLSM and monitored carbohydrate distribution in an extracellular matrix. On the other hand, sample preparation in these techniques is extensive. Staining 
brings additional cost and due to staining, simultaneous analysis of multiple components in biofilms is not an easy task. The assembly of a biofilm structure on a solid surface can be examined with scanning electron microscopy (SEM) and transmission electron microscopy (TEM) after a fixation procedure. Although the distribution of cells and the polymeric matrix can be excellently monitored, these microscopy techniques are not able to monitor living biofilm structures [9]. The other important microscopy technique is scanning transmission X-ray microscopy (STXM), which is extensively used in mapping biofilm composition without using a probe and also with reduced radiation damage on the sample. STXM is used to monitor not only the polymeric substances but also allows the metal distribution to be viewed. On the other hand, errors in reference spectra and absorption saturation limit the use of this technique [10]. Atomic force microscopy (AFM) is the most general technique used to gain information from the depth of the surface topography, and this feature allows the distribution of the extracellular polymeric substances to be displayed [11]. However, it is time consuming to use when characterizing larger areas of a heterogenic biofilm structure due to its low scanning speed.

Nuclear magnetic resonance (NMR) is another technique used to obtain structural information on the substances in biofilm matrices [12]. Although the technique gives an opportunity to acquire information in situ from a biofilm, it is not suitable for characterizing high molecular weight molecules due to the complexity of interpreting the obtained data [13]. Separating EPS from the biofilm matrix is another preferred method in characterizing the components. Extraction by centrifugation or using chemical additives, solid phase extraction with liquid chromatography (LC) and field-flow fractionation are new approaches and the main techniques used in several studies [14]. The identification of biofilm-associated genes of a microorganism can be carried out using molecular techniques, as well as analytical techniques. A combination of the widely used molecular techniques, gel electrophoresis, and polymerase chain reaction (PCR) with microscopic and spectroscopic techniques has revealed gene regulation profiles during biofilm formation [15]. Understanding polysaccharide, protein, and lipid profiles in biofilms was also achieved by separating the matrix with a chromatography column and then identifying the profiles with sensitive and high technology mass spectrometry techniques such as matrix-assisted laser desorption ionization mass spectrometry (MALDI-MS), electrospray ionization mass spectrometry (ESI-MS) or nano-ESI-MS, ESI-tandem MS, ESI-MS-MS, and LC-MS-MS [16,17]. However, chromatography and MS-based techniques are destructive, expensive, and time consuming. In addition, complex sample preparation steps are needed.

In addition to the techniques mentioned above, the vibrational spectroscopic techniques have been used to obtain information about the biofilm structure at a molecular level. Infrared and Raman spectroscopies are vibrational spectroscopy techniques used complementary to each other to acquire spectral information on the molecular structure of biofilms. Although infrared spectroscopy (IR) is widely used for characterizing biofilms, interference from water has limited its use in the composition of hydrated biofilms [18]. The spectral -OH band attributed to water suppresses the other characteristic bands of the components in a biofilm. Raman spectroscopy is based on Raman scattering, which occurs when photons scatter from the molecule with either lower or higher frequency than the frequency of the incident light [19]. Since the frequencies of the scattered photons depend on the types of bonds in the molecule, the Raman spectrum of each molecule is unique and can be considered as a fingerprint of that molecule. Diffraction-limited spatial resolution of Raman spectroscopy is around $1 \mu \mathrm{m}$, which enables detailed analysis of complex structures containing various kinds of molecules and molecular groups such as proteins, carbohydrates, lipids, and nucleic acids. In addition to this remarkable feature, it is a non-destructive technique; therefore, sample preparation is easier than the other techniques. There is no need to stain samples and also no need to dry them because Raman scattering of water is very weak compared to other molecules (e.g., there is not any interference from water in Raman spectroscopy). We refer the readers to the other three reviews for detailed information about its use for characterizing biological structures [19-21]. Although Raman spectroscopy can be a useful tool for many research areas, weak Raman scattering hampers the use of this technique when a lower limit of detection is desired for a molecule of interest. In addition, acquisition of spectra from 
biomolecules may take a longer time due to their poor Raman scattering nature and may require higher laser power ending up damaging the sample. In surface-enhanced Raman scattering (SERS), the Raman scattering from a molecule in the close vicinity of a nanostructured noble metal surface such as silver or gold is easily enhanced up to $10^{7}$ times [22,23]. The enhancement mechanism is attributed to the combined effect of both an electromagnetic (through localized surface plasmon resonance) and a chemical (through charge transfer upon contact of a molecule to nanostructured surface) enhancements. As a result, the sensitivity in SERS is significantly increased and the detection limit is lowered. For more information on the biological applications of SERS other than in biofilms, we refer the readers to review articles published recently [24,25]. Although the enhancement in scattering makes SERS suitable for many applications in several fields, there are still some challenges preventing the implementation of this technique widely including clinical applications. First, the choice of the SERS substrate is the most important factor due to the issues with the enhancement factor and spectral reproducibility. Another issue is the selective enhancement of the spectral bands observed on a spectrum. Since noble metal nanoparticles used as SERS substrates have specific affinity for certain functional groups such as thiols and amines, obtaining spectral information from low-affinity molecular components of biofilms can be limited and molecular moieties close to the noble metal surface can dominate the spectrum. To overcome this problem, SERS substrates can be functionalized with certain chemical groups to provide an affinity for the target biomolecules. Another issue is the spectral variations in the spectra of the same molecules or molecular structures from laboratory to laboratory. There is no worldwide accepted and applied protocol for spectra acquisition from cells, tissues, microorganisms, etc., which also prevents the implementation of this technique in clinics. On the other hand, we are hopeful that with fruitful collaborations at least some of the issues with the application of SERS in clinics will be solved in the near future.

In this review, Raman spectroscopy and SERS-based studies on biofilms are discussed. The first part focuses on the significant developments in the use of Raman spectroscopy for characterizing biofilm structures. The second part includes applications of the SERS technique for biofilm characterization, detection of quorum sensing molecules, and the identification and discrimination of biofilms of a variety of microorganisms.

\section{Raman Spectroscopy of Biofilms}

The initial reports regarding the use of Raman spectroscopy in biofilm research focused on the investigations of diffusion and distribution processes of certain molecules in the biofilm structure. Nearly two decades earlier, Suci et al. [26] have studied the spatiotemporal distribution of an antibacterial and antifungal agent, chlorhexidine, in Candida albicans biofilms. Both attenuated total reflectance (ATR)-Fourier transform infrared (FTIR) spectroscopy and Raman spectroscopy results have shown that the diffusion coefficient for the transport of chlorhexidine through biofilms with $200 \mu \mathrm{m}$ thickness was less than the diffusion coefficient for chlorhexidine in water. It was also shown that the chlorhexidine concentration was higher in the outer regions of the thick biofilms due to its adsorptive behavior. In another report, diffusion of polyethylene glycol and hydrogen-deuterium oxide (HOD) in Streptococcus mutans biofilms was monitored [27]. Hydrated biofilms were mapped in $\mathrm{x}, \mathrm{y}$, and $\mathrm{z}$ directions. HOD could diffuse everywhere in the biofilm. On the other hand, polyethylene glycol diffusion rate was diverse in different parts of the biofilm due to the heterogeneous structure of the biomass.

Raman spectroscopy has also been used for analyzing the composition and structure of bacterial colonies. Choo-Smith et al. [28] analyzed the colony structure of two strains of Staphylococcus aureus, two strains of Escherichia coli and a strain of Candida albicans by acquiring Raman spectra from various positions within the colonies after their growth for 6, 12, and $24 \mathrm{~h}$. At the sixth hour, microcolonies were very homogenous, indicating that the 6-h culture is more suitable for classification purposes. On the other hand, they were heterogeneous at 12 and $24 \mathrm{~h}$. Spectra obtained from different positions within single colonies revealed the presence of more than one layer in the colonies. Moreover, it was 
found that RNA concentration was higher in the deeper levels and glycogen amounts were higher on the surface of the colonies.

To investigate the effects of the initial age of bacterial cells for biofilm development, Enterococcus faecalis was investigated as the bacterial model. It is a commensal bacterium living in the intestinal tract and can cause infections after root canal treatment [29]. Biofilm matrices were prepared using bacterial cells in the exponential, stationary, and starvation phases, and their Raman spectra were acquired. It was found that the biofilms formed with the inoculation of bacterial cells in the starvation phase included more protein but less nucleic acid than the biofilms originating from exponential and stationary phase cells.

Detailed analyses of biofilm compositions were performed by Sandt et al. [30]. They investigated the structure and composition of hydrated biofilms grown in a flow cell using, for the first time, confocal Raman microscopy. Raman mapping of Pseudomonas aeruginosa PAO1 biofilms were performed for 3 weeks, from the beginning of the initial attachments to the formation of EPS in the biofilm. During the initial phase of the biofilm formation, variations among the acquired spectra were minor. On the other hand, spectra became highly variable in time due to the enriched composition of the biofilm. In order to analyze the source of the peaks in the collected spectra, biofilms were washed with EDTA to remove unbound EPS, and sharp spectral features attributed to EPS were obtained in difference spectra. In the other report [31], they analyzed water content and biomass density of wild-type (WT) Pseudomonas aeruginosa PAO1, small colony variant (SCV) PAO1, and Pseudoalteromonas ssp. NCIMB 2021 biofilms. Intensity ratios of the O-H band of water at $3450 \mathrm{~cm}^{-1}$ and $\mathrm{C}-\mathrm{H}$ band at $2950 \mathrm{~cm}^{-1}$ on the mapped biofilm surfaces were used to find water to biomass ratios of the biofilms (Figure 1). Protein (BSA) solutions were used as standards to compare relative hydration.

A



C

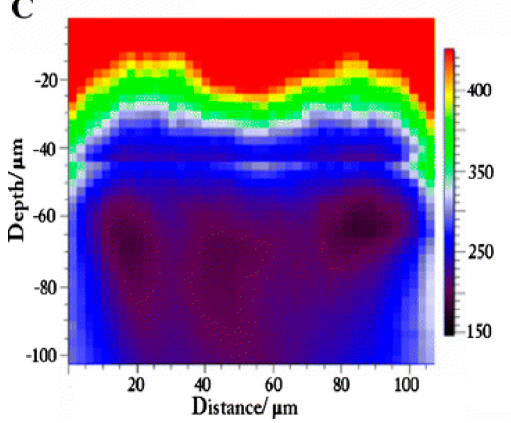

B

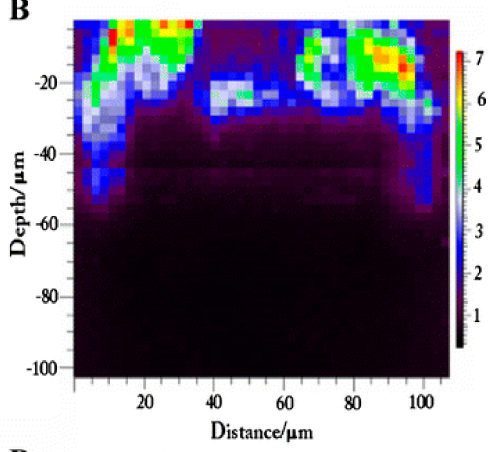

D

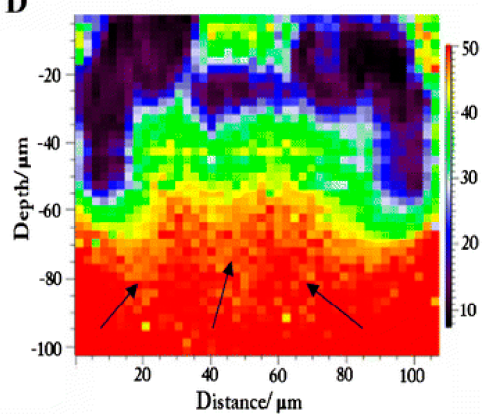

Figure 1. Colony in a pure small colony variant (SCV) PAO1 biofilm 21 days after inoculation, showing cavities filled with water and little biomass in the core of the colony. (a) Bright field image. Raman spectra $\left(1084 \mathrm{~cm}^{-1}\right)$ were collected every $2.5 \mu \mathrm{m}$ in a plane extending down from the line shown through the colony in a. (b) Map of $\mathrm{CH}_{3}$ signal (3300-3500 $\mathrm{cm}^{-1}$, biomass). (c) Map of $\mathrm{OH}$ signal (2905-2965 cm $\mathrm{cm}^{-1}$, water). (d) Map of water to biomass ratios (W/BRs). The arrows indicate the presence of streamers. The intensity scale for $\mathrm{b}$ and $\mathrm{c}$ (right-hand side of the figures) goes through blue to red as the peak area/1000 increases. The intensity scale for $d$ goes through blue to red as the W/BR increases. Reproduced with permission from Springer [31]. 
In this context, Samek et al. acquired Raman spectra of the biofilm-forming Staphylococcus epidermidis 1457 strain and its non-biofilm-forming mutant Staphylococcus epidermidis 1457-M10 strain after growth of each on Columbia blood agar culture plates for $24 \mathrm{~h} \mathrm{[32].} \mathrm{Although} \mathrm{there} \mathrm{were} \mathrm{subtle}$ differences between the spectra of the two strains, the principal component analysis (PCA) of the spectra clearly discriminated the two strains and showed the effects of the biofilm matrix ingredients on the spectra, especially that of polysaccharide inter-cellular adhesions (PIA). Beier et al. [33] discriminated two oral bacteria species, Streptococcus sanguinis and Streptococcus mutans, in their hydrated biofilm mixtures using a classification algorithm that was previously developed by using their dried biofilms.

Raman spectroscopy has also been used to investigate the formation of different EPS types during biofilm growth. EPS is divided into two groups: soluble EPS and bound EPS. The latter again includes two groups: tightly bound and loosely bound EPS. Chen et al. [34] investigated the characteristics of the functional groups of these four types of EPS obtained from biofilms grown on two different biomass carriers in reactors and found that protein and polysaccharide amounts of tightly bound EPS in one kind of carrier were higher than the other.

Ivelva et al. [35] made a systematic study by acquiring Raman spectra of various biofilm ingredients such as polysaccharides, alginates, proteins, and spectra from free Escherichia coli and Raoultella planticola cells and their encapsulated forms, and used these data to gain in-depth knowledge about the origins of Raman spectra of multispecies biofilms.

The comparison of Raman spectra of planktonic cells and their biofilm forms gives invaluable information about biofilm formation and development. Huang et al. [36] compared Raman spectra of planktonic cells of Pseudomonas fluorescens SBW25 and cells obtained from its biofilm form were grown in King's B medium for 3 days. The principal component-discriminant function analysis was used to discriminate between the spectra of the two groups and showed that metabolic status and environmental conditions had significant effects in that discrimination. Sharma et al. [37] characterized planktonic and biofilm cells of Cronobacter sakazakii, which cause infant meningitis. Comparison of the spectra of the two different forms of this opportunistic bacteria showed that the intensity of the bands assigned to carbohydrates, lipids, carotenoids, DNA, and tyrosine were more prominent in biofilm spectra.

Kusić et al. [38] studied planktonic cells and biofilms of six Legionella strains, as well as Pseudomonas aeruginosa, Klebsiella pneumoniae, and Escherichia coli species. Comparison of the Raman spectra of L. pneumophila and Pseudomonas aeruginosa grown in tap water and artificial media revealed an increased lipid and decreased DNA content in bacterial cells as an adaptation to nutrient-limited environmental conditions. Biofilms of Legionella strains had higher lipid content whereas biofilms of Pseudomonas aeruginosa, Klebsiella pneumoniae, and Escherichia coli had higher polysaccharide content relative to their planktonic cellular states. Subsequent support vector machine (SVM) analyses on Raman spectra of biofilms and planktonic cells resulted in more than $90 \%$ accuracies in their classifications. In another related report [39] by the same group, bacterial cells of Legionella species were isolated from their biofilms using immunomagnetic separation and identified on a single cell level using multivariate analysis. Implemented techniques were not involved in any cultivation step. An overall accuracy of $98.6 \%$ was achieved for the discrimination of isolated Legionella cells from Pseudomonas aeruginosa, Klebsiella pneumoniae, and Escherichia coli cells. In addition, an accuracy of $86.3 \%$ was obtained for the classification of five different Legionella strains.

Using different instruments for an experiment always brings new dimensions and gives comprehensive information about the matter of investigation. In this context, when the power of Raman spectroscopy is combined with that of CLSM, a better understanding of biofilm composition and its structure could be obtained. A good example of this was demonstrated by Wagner et al. [40]. For 92-day-old biofilms, CLSM analysis could not detect any composition change of the EPS. On the other hand, Raman spectroscopy showed a change in the composition of polysaccharides to glycoproteins.

A detailed analysis reported by Andrews et al. [41] showed the power of combining CLSM and Raman spectroscopy for a deeper understanding of cell attachment and biofilm growth. A total of 
11 bacterial strains including species of Rhodococcus, Pseudomonas putida, Sphingomonas, Acidovorax, and Duganella were used for the study. It was found that attachment behavior of bacterial cells on different surfaces and subsequent biofilm growth was influenced by several extracellular macromolecules such as lipids, proteins, and nucleic acids, and the effects of these molecules were genus specific.

Feng et al. [42] developed a microfluidic lab-on-a-chip device to study Pseudomonas aeruginosa biofilms using both Raman spectroscopy and CLSM. They measured biofilm thickness using CLSM at different time periods and characterized biofilm composition with Raman spectroscopy. Comparison of the acquired spectra at different growth stages revealed that the major constituents of the biofilm at a mid-stage of biofilm development were similar to an early stage. After $48 \mathrm{~h}$, the biofilm was in the late stage and production of carbohydrates and proteins was much more than nucleic acids. Further validation was achieved by discrimination of the Raman spectra of each stage using PCA.

CLSM was not the only technique used in combination with Raman spectroscopy to elucidate the composition and the structure of biofilms. Recently MALDI-MS was used with Raman spectroscopy and it was found that although nucleic acid bands were prominent for planktonic cells, glycolipids, rhamnolipids, and carbohydrate bands were more dominant in the case of biofilms [43]. MALDI-MS was used to obtain chemical information about rhamnolipid species; nine different species were found. In another study, the same group showed the presence of quinolone signaling molecules in Pseudomonas aeruginosa biofilms using Raman spectroscopy for the first time and analyzed the distribution of quinolone species with secondary ion mass spectrometry (SIMS) [44].

Since many studies have reported on the application of Raman spectroscopy for biofilm structure and composition, it was very unlikely that the effects of antimicrobial agents on biofilms using the same technique had not been investigated. For example, Lu et al. [45] showed antimicrobial effects of diallyl sulfide on the biofilms of Campylobacter jejuni, a bacterium that can cause gastrointestinal diseases. The chemical compositions of planktonic cells and biofilms were compared and EPS recalcitrance modes against antimicrobial agents (ciprofloxacin erythromycin, and diallyl sulfide) were demonstrated. It was found that diallyl sulfide was effective on biofilms at a concentration 100-fold less than the other two antimicrobial agents.

The effects of antibiotics on Pseudomonas aeruginosa biofilms have also been shown [46]. Biofilms grown in a microfluidic device were monitored with CLSM and their composition was characterized by Raman spectroscopy in the presence of three antibiotics (ceftazidime, patulin, and epigallocatechin gallate; EGCG). Upon exposure to antibiotics, an intensity decrease in the protein and nucleic acid bands were observed. Moreover, in ceftazidime and patulin-treated biofilms, carotenoid accumulation was detected. In another study, the antimicrobial activity of papain functionalized polycaprolactam as a food packing material was tested against Escherichia coli biofilms [47]. Intensity changes of many Raman bands attributed to functional groups showed inhibition of biofilm formation.

Since Raman scattering of many biomolecules is very weak, implementation of resonance Raman spectroscopy (RRS) provided another dimension for in-depth analysis [48]. Resonance Raman scattering occurs when the excitation wavelength of the laser couples with the wavelength at which the targeted molecule absorbs the light at maximum level, and is at least 100 times more intense than Raman scattering. Therefore, use of a suitable laser wavelength makes it a lot easier to find certain molecules in biofilms. One of these molecules is cytochrome c. Pätzold et al. [49] used resonance enhancement of cytochrome $c$ to find the distribution of nitrifiers and Annamox bacteria in their natural environment. In addition, bacteria could be grouped at the strain level using the heterogeneity of spectrum of cytochrome $\mathrm{c}$ in different exposure times and culture conditions. In this context, Kniggendorf et al. [50] developed coexisting microcolonies of Nitrosomonas on granules from two sequencing batch reactors and mapped with resonance Raman spectroscopy. The spectra obtained were compared with reference spectra of bacteria. As a result, Nitrosomonas communis Nm02 was identified with $94 \%$ certainty and Nitrosomonas europaea with $80 \%$ certainty.

Thus far, the application of Raman spectroscopy and its special form resonance Raman spectroscopy were reviewed. Both techniques provide fingerprint molecular information on the 
analyte of interest and hence are extremely useful for bacterial biofilm studies. On the other hand, weak Raman scattering for biomolecules and the limited number of molecules that can be used for resonance studies limit the use of both techniques. Surface-enhanced Raman scattering (SERS), on the other hand, provides more enhancement and lowers the detection limits of the molecule of interest. In the next section, applications of SERS for biofilm analyses are provided.

\section{Surface-Enhanced Raman Scattering of Biofilms}

\subsection{Identification of Spectral Signatures in a Biofilm}

The application of SERS in biofilm characterization has become promising with the studies published for the last 10 years. Clarification of the biochemical origins of the SERS signals in a biofilm and determining the spectral signatures and biomarkers specific to the microorganisms could help widen the use of SERS in different clinical settings. The first study showing the applicability of SERS in biofilm characterization was published by Ivleva et al. [51] in 2008. In the study of Ivleva et al., protozoa cells and their biofilm structure was identified with SERS. The biofilm was grown in a reactor and was cultivated on a glass slide. Hydroxylamine hydrochloride-reduced silver nanoparticles (AgNPs) were used as SERS substrates and the biofilm-coated glass slides were immersed into the silver colloidal suspension and the SERS measurements were performed. The peaks at $1382 \mathrm{~cm}^{-1}$ and $1585 \mathrm{~cm}^{-1}$ were identified in the SERS spectrum of protozoa cells belonging to $\mathrm{COO}^{-}$symmetric and asymmetric stretching vibrations of amino acids and polysaccharides. Apart from the cell spectra, the bands at $734 \mathrm{~cm}^{-1}$ and $1355 \mathrm{~cm}^{-1}$ attributed to polysaccharides were observed in the SERS spectra of protozoa biofilms. It was defined that these two dominant peaks could be used as a polysaccharide marker in a biofilm structure. Characterization of a heterotrophic biofilm structure was also demonstrated by Ivleva et al. [52] under the same conditions as the previous study mentioned above. Dominant peaks on the biofilm spectra were consistent with their previous study [51]. The dominant peaks were identified at 1555,1380 , and $1280 \mathrm{~cm}^{-1}$ with maximum intensities. The peak at $1380 \mathrm{~cm}^{-1}$ belonging to polyanionic polysaccharides distributed in the biofilm matrix and this specific peak was assigned as a marker for polyanionic polysaccharide in the biofilm matrix. Also, the peak at $1280 \mathrm{~cm}^{-1}$ was attributed to $\mathrm{COH}, \mathrm{HCO}$, and $\mathrm{HCC}$ deformation, $\mathrm{COO}^{-}$stretching symmetric, and C-O stretching. In addition, the phenylalanine ring breathing peak observed at $1000 \mathrm{~cm}^{-1}$ could be used as a protein signature in a biofilm.

Biofilm formation consists of adhesion, colony formation, and maturation phases [53]. Monitoring the structural changes in biofilms at different time points of their growth with SERS can provide in-depth understanding of biofilm formation processes. In this context, Chao et al. [54] studied the formation Escherichia coli, Pseudomonas putida, and Bacillus subtilis biofilms between 0 and $72 \mathrm{~h}$ of growth with SERS using hydroxylamine hydrochloride-reduced AgNPs. Biofilms were grown on quartz windows and then $200 \mu \mathrm{L}$ AgNPs was added on the substrates, which were incubated until dry before SERS measurements. The determined main peaks on the SERS spectra were 479, 730, 980, 1320, and $1145 \mathrm{~cm}^{-1}$ belonging to carbohydrates, nucleic acids, proteins, and lipids. Indeed, the biofilms formed by Gram-negative bacteria (Escherichia coli and Pseudomonas putida) and Gram-positive bacteria (Bacillus subtilis) could be discriminated based on the peaks observed at 659, 1112, and $1366 \mathrm{~cm}^{-1}$, which were attributed to tyrosine, lipids, and proteins. The main goal of the study was to monitor changes in the SERS spectral pattern during biofilm formation. The deterministic peaks of Escherichia coli were observed at $659,730,1320$, and $1445 \mathrm{~cm}^{-1}$ with pattern differences from the previous studies [55-59]. The differences were explained in that study by changes in the bacterial strain, growth conditions, instrumentation, and SERS substrates. In the study of Chao et al., the regulation of biofilm processes was also evaluated based on the expression profiles of carbohydrates, proteins, DNA content, and lipids. The key peaks of the polysaccharides were defined as the peaks observed at 409, 479, and $565 \mathrm{~cm}^{-1}$ with an increase in the intensity profile during maturation. Protein enrichment was observed after $72 \mathrm{~h}$ incubation with an intensity increase in the peaks of tyrosine, phenylalanine, amide I, amide II, and amide III at 659, 1005, 1616, 1571, and $1242 \mathrm{~cm}^{-1}$. Also, extracellular DNA 
(eDNA) expression was identified according to the peak at $730 \mathrm{~cm}^{-1}$ in the adhesion phase. The peaks between 1440 and $1445 \mathrm{~cm}^{-1}$ were used to investigate changes in the lipid content of the biofilm and it was found that Gram-negative bacteria expressed high amounts of lipid during maturation.

Understanding biofilm composition and discrimination of the biofilm formations of different microorganisms using SERS has become an important research field because it provides an opportunity to apply the technique to heterogenic clinical settings. In this context, differentiation of algae and bacterial biofilms grown on titanium surfaces was showed with Raman mapping coupled with SERS technique using Ag/Cu colloids. The titanium surfaces with biofilms were immersed in a colloidal suspension before the characterization. It was demonstrated that while algae biofilms contain a polysaccharide-rich matrix, protein is the major component in the bacterial biofilms [60].

Biofilm formation of Escherichia coli and Staphylococcus aureus were also monitored in situ by our group using chitosan-coated AgNPs (c-AgNPs) as a SERS substrate [22]. Chitosan was used as a biological semipermeable barrier in the complex biofilm structure and it also prevented dissolution of AgNPs. Chitosan contains $-\mathrm{NH}_{2}$ groups, which can increase the interaction of positively charged c-AgNPs with the negatively charged molecules in biofilms, which was different from the previous studies. The biofilms were grown on agar plates and $10 \mu \mathrm{L}$ c-AgNPs were dropped on the surfaces; measurements were performed after a 10 min incubation. It is known that DNA/RNA components are negatively charged and it was expected that DNA/RNA components would be observed on the SERS spectra of biofilms. With this aim, SERS spectra of oligonucleotides of adenine, thymine, guanine, and cytosine were obtained using c-AgNPs as a database for the measurements. It was found that the peaks observed on the SERS spectra of Escherichia coli and Staphylococcus aureus biofilms at 678,802 , and $1570 \mathrm{~cm}^{-1}$ could be attributed to DNA/RNA components because these peaks were significantly observed on the spectrum of pristine oligonucleotides. Indeed, it was demonstrated that the general spectral patterns in a two-microorganism model were significantly different during biofilm formation. Additionally, microorganism death was observed with SERS in another study published by our group [61]. Escherichia coli was selected as the model microorganism and was exposed to ampicillin for 2, 4, and $6 \mathrm{~h}$. Changes in molecular activity of the bacteria were clearly observed with increasing exposure time to the antibiotic, as seen in Figure 2. In particular, the peak observed at $678 \mathrm{~cm}^{-1}$, which shows a significant change in the spectrum after $6 \mathrm{~h}$, is thought to be attributed to DNA and RNA components being released after disintegration of the bacterial cell wall, which can be used as a distinctive spectral feature for monitoring bacterial death.

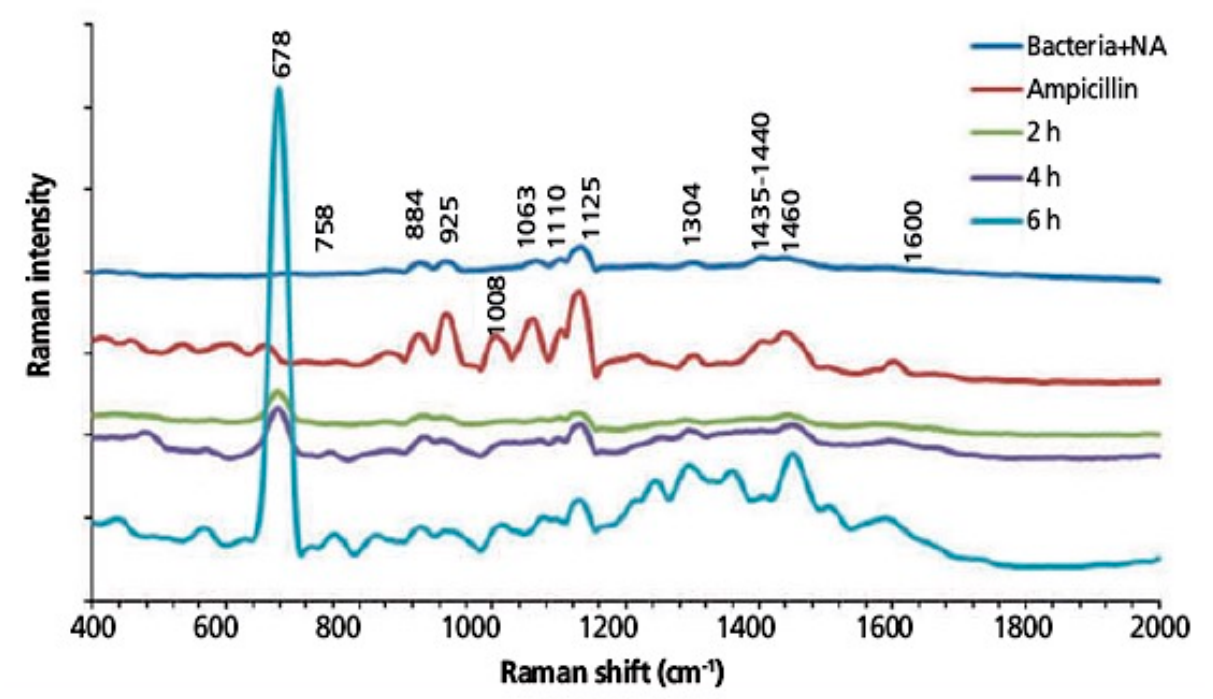

Figure 2. Surface-enhanced Raman scattering (SERS) spectra obtained during the death of E. coli with ampicillin exposure. NA: Nutrient agar [61]. 


\subsection{Detection of Quorum Sensing Molecules}

Quorum sensing is a chemical communication system for microorganisms in a biofilm structure. The microorganisms produce chemical signals called autoinducers that diffuse across the cell membrane. When these signal molecules reach a threshold concentration, they bind to receptors the on bacteria, which leads to gene regulation [62]. Quorum sensing is essential for the production of virulence factors and for growth of the biofilm. These molecules could be used as a biofilm reagent in SERS measurements. In this context, Pearman et al. [62] acquired SERS spectra of N-acyl homoserine lactones (AHLs), which are expressed by Gram-negative bacteria and possess acyl chain lengths from 4 to 12 carbons, using colloidal borohydride and citrate-reduced AgNPs. The peaks of amide I, amide II, amide III, and amide IV at 1648, 1570, 1308 and $771 \mathrm{~cm}^{-1}$ were observed clearly in all of the AHLs' spectra; the most significant peak was determined as amide I. The observed spectral differences at around $1200 \mathrm{~cm}^{-1}$ and at $1533 \mathrm{~cm}^{-1}$ among the spectra of AHLs with different acyl chain lengths were found as useful for their identification and discrimination. The obtained spectra of autoinducers in this study can be useful for their detection in biofilm matrices in future work.

Pseudomonas aeruginosa is a pathogenic bacterium known to cause cystic fibrosis [63] and is generally used as a model microorganism in studies identifying virulence factors and quorum sensing molecules in biofilms. Pyocyanin is a blue-green toxic molecule that acts as a virulence factor. It is a member of the quorum sensing system of Pseudomonas aeruginosa and is used as a biomarker for this bacteria species. The first study about the detection of pyocyanin in biofluid samples with SERS was performed by Wu et al. [64] in 2014. Pyocyanin was detected in clinical sputum samples with 95.6\% sensitivity and $93.3 \%$ specificity using a silver nanorod array as the SERS substrate. The achieved limit of detection for pyocyanin was $5 \mathrm{ppb}$, which shows the potential use of this technique in the clinic for the early diagnosis of Pseudomonas aeruginosa infections. The other outcome of this study was that the characteristic SERS spectral peaks of pyocyanin at $1088,1125,1352$, and $1613 \mathrm{~cm}^{-1} \mathrm{could}_{\text {be }}$ extremely useful for the identification of Pseudomonas aeruginosa biofilms using SERS. In this context, novel plasmonic substrates were fabricated for label-free detection of pyocyanin with surface-enhanced resonance Raman scattering (SERRS) in a recent study (Figure 3) [65]. The study showed the efficiency of three differently designed plasmonic substrates as sensors for pyocyanin detection. Macroporous poly-N-isopropylacrylamide hydrogels loaded with Au nanorods and a mesostructured substrate with a mesoporous $\mathrm{TiO}_{2}$ thin film over a submonolayer of Au nanospheres were produced and their efficient use for the characterization of a biofilm at early and mature phases was demonstrated. Mesoporous silica-coated micropatterned supercrystal arrays of Au nanorods were fabricated as a third sensor, which lowered the detection limit of pyocyanin due to its better SERS enhancing property. SERS detection of pyocyanin was performed for both planktonic cultures and biofilms grown on these plasmonic substrates. In addition, the designed sensors were implanted in mice to demonstrate their potential use for detecting small biomolecules in chaotic biofilm structures and for the screening of antimicrobial drugs. In a study by Polisetti et al. [66], pyocyanin was secreted from both clinic and laboratory strains under different nutritional support and was revealed-using SERS imaging and principal component analysis-as a key molecule in the Pseudomonas aeruginosa biofilm. Sodium borohydride-reduced AgNPs were used as SERS substrates and biofilm samples were grown in sterile tubes. Biofilm samples with AgNPs dropped on silicon wafers were incubated until dry before characterization with SERS. In this study, C-C stretching, C-N stretching, and C-H in-plane bend modes were assigned as a marker peak of pyocyanin observed at $1354 \mathrm{~cm}^{-1}$ from the spectral data and SERS was proposed as a high-potential technique for chemometric analysis. 

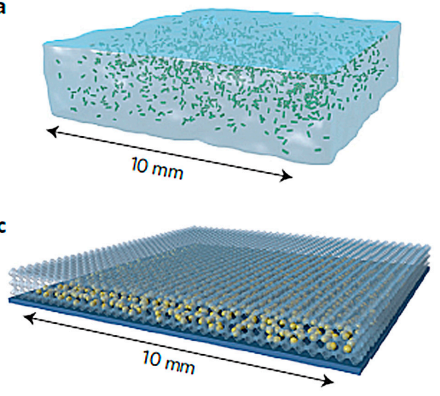

e

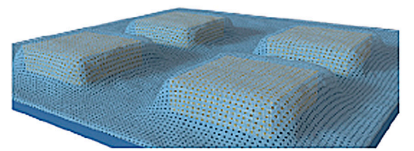

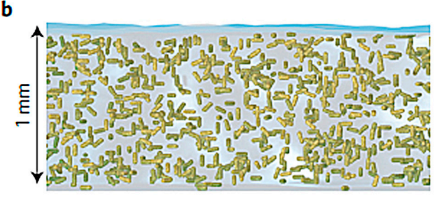
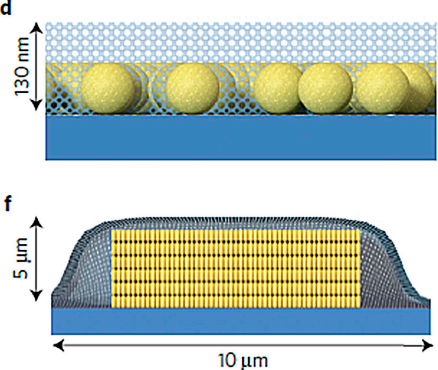

Figure 3. Schematic representation of nanostructured porous substrates for in situ plasmonic detection and imaging of QS in Pseudomonas aeruginosa biofilms. (a,b) Au@pNIPAM hydrogel with embedded $\mathrm{Au}$ nanorods (drawn in green). (c,d) Mesostructured $\mathrm{Au} @ \mathrm{TiO}_{2}$ substrate with a mesoporous $\mathrm{TiO}_{2}$ thin film over a submonolayer of Au nanospheres. (e,f) Micropatterned $\mathrm{Au} @ \mathrm{SiO}_{2}$ supercrystal array comprising Au nanorods organized in micrometer-sized pedestal-like structures coated with mesoporous silica. Panels $(\mathbf{b}, \mathbf{d}, \mathbf{f})$ represent cross-sectional views. Reproduced with permission from Nature [65]. Copyright (2016) Nature Materials.

\subsection{Identification and Discrimination of Biofilms}

Biofilms can be formed either by one type of microorganism or by a mix of microorganisms [67]. Therefore, development of novel methods to detect each type of microorganism in the complex environment of biofilms is extremely important. It is also important to know the kinds of biomolecules in both single-species and multi-species biofilms to be able to develop new kinds of drugs, antimicrobials etc. SERS can be an invaluable tool for these aims. Chen et al. [68] compared the SERS spectra of the biofilms composed of both Brevundimonas diminuta and Staphylococcus aureus to the spectra of biofilms formed by only one of these two bacterial species. Biofilms were grown on mixed cellulose ester membranes and gold nanoparticles (AuNPs) were dropped on biofilm samples before SERS measurements. SERS spectra of single-species biofilms and dual-species biofilms were acquired and compared at different time periods ( $1 \mathrm{~h}, 4 \mathrm{~h}, 8 \mathrm{~h}, 24 \mathrm{~h}, 48 \mathrm{~h}, 72 \mathrm{~h})$ during microorganism growth. It was observed that acquired spectra were in good agreement with the SEM images of the biofilms collected at these time periods. The SERS peaks that were useful for the discrimination of two model microorganisms' single-species biofilm were adenine peaks at 733 and $1340 \mathrm{~cm}^{-1}$, guanine peaks at 665,1340 , and $1584 \mathrm{~cm}^{-1}$, amide I band at $1704 \mathrm{~cm}^{-1}, \mathrm{C}-\mathrm{H}$ bending of proteins at $1028 \mathrm{~cm}^{-1}$, a lipid peak at $1460 \mathrm{~cm}^{-1}$, and the peak at $1330 \mathrm{~cm}^{-1}$ attributed to DNA bases. PCA of the spectra obtained from planktonic and biofilm forms of the microorganisms were used to find dominant species in dual-species biofilms at different time periods.

In our recent publication, we focused on monitoring biofilm formation of clinically relevant microorganisms [69]. Citrate-reduced AgNPs were used as SERS substrates and the biofilm formations of Pseudomonas aeruginosa, Staphylococcus epidermidis, and Candida albicans were evaluated on agar plates at different time points between 4 and $120 \mathrm{~h}$ of biofilm growth. Citrate-reduced AgNPs were used in this study. A colloidal suspension $(10 \mu \mathrm{L})$ was dropped on the biofilm samples and then incubated for $10 \mathrm{~min}$ for interaction of the AgNPs with the biofilm components. The objectives of the study were to define the biofilm formation steps of the model microorganisms at a molecular level and to show the efficiency of the SERS technique for classifying the different biofilms based on the unique metabolic processes of microorganisms using PCA. Significant changes in the SERS spectra of biofilms were observed during biofilm maturation. The SERS spectra of the Pseudomonas aeruginosa biofilm at 
different time points are given as an example in Figure 4. For the Candida albicans biofilm, a significant protein, lipid, and carbohydrate enrichment was observed at the incubation times of 24 and 48 h. These molecular composition changes were effective for discriminating yeast biofilm spectra from bacterial biofilm spectra. The findings of this study can be helpful for the potential use of SERS for identifying discriminatory biofilms of pathogenic microorganisms in clinical settings. A summary list of the SERS applications in biofilm detection is provided in Table 1.

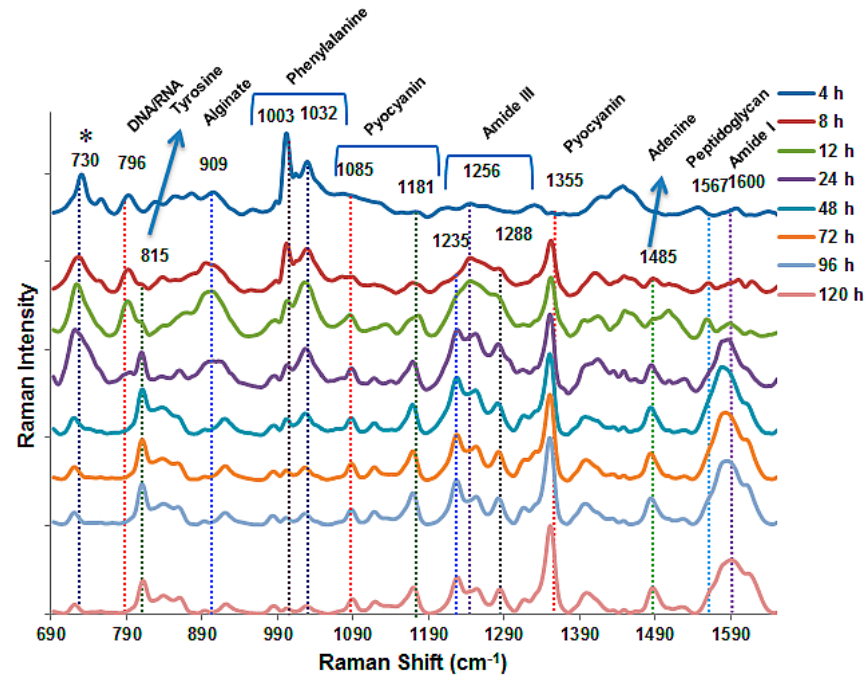

Figure 4. SERS spectra of biofilm formation of Pseudomonas aeruginosa at cultivation times between 4 and $120 \mathrm{~h}[69]$.

Table 1. A list of SERS studies mentioned in the "Surface-enhanced Raman scattering of biofilms" section.

\begin{tabular}{|c|c|}
\hline Type of Microorganism & Output \\
\hline Protozoa cells & Characteristic peaks of polysaccharides $\left(1382,1585 \mathrm{~cm}^{-1}\right)[51]$ \\
\hline Heterotrophic biofilm & Polyanionic polysaccharides $\left(1380 \mathrm{~cm}^{-1}\right)$, phenylalanine $\left(1000 \mathrm{~cm}^{-1}\right)[52]$ \\
\hline $\begin{array}{l}\text { Escherichia coli } \\
\text { Pseudomonas putida } \\
\text { Bacillus subtilis }\end{array}$ & $\begin{array}{l}\text { Microorganisms were discriminated based on the peaks of tyrosine }\left(659 \mathrm{~cm}^{-1}\right) \text {, } \\
\text { lipids }\left(1112 \mathrm{~cm}^{-1}\right) \text {, proteins }\left(1366 \mathrm{~cm}^{-1}\right) \text {. } \\
\text { Identification of the changes in the spectral pattern during biofilm formation [54] }\end{array}$ \\
\hline $\begin{array}{l}\text { Algae and } \\
\text { Pseudomonas aeruginosa }\end{array}$ & $\begin{array}{l}\text { Algae biofilms contain a polysaccharide-rich matrix } \\
\text { Bacteria biofilms contain a protein-rich matrix [60] }\end{array}$ \\
\hline $\begin{array}{l}\text { Escherichia coli } \\
\text { Staphylococcus aureus }\end{array}$ & DNA/RNA components $\left(678,802\right.$, and $\left.1570 \mathrm{~cm}^{-1}\right)$ [22] \\
\hline Escherichia coli & $\begin{array}{l}\text { Distinctive spectral features for monitoring bacterial death (DNA/RNA components, } \\
678 \mathrm{~cm}^{-1} \text { ) [61] }\end{array}$ \\
\hline Pseudomonas aeruginosa & Detection of pyocyanin $\left(1088,1125,1352\right.$ and $\left.1613 \mathrm{~cm}^{-1}\right)[64]$ \\
\hline Pseudomonas aeruginosa & Plasmonic substrates were fabricated and used in label-free detection of pyocyanin [65] \\
\hline Pseudomonas aeruginosa & $\begin{array}{l}\text { C-C stretch, C-N stretch, and C-H in-plane bend modes were assigned as a marker } \\
\text { peak of pyocyanin [66] }\end{array}$ \\
\hline $\begin{array}{l}\text { Brevundimonas diminuta } \\
\text { Staphylococcus aureus }\end{array}$ & $\begin{array}{l}\text { Discrimination peaks for the two-species model were determined } \\
\text { Adenine }\left(733 \text { and } 1340 \mathrm{~cm}^{-1}\right) \text {, guanine }\left(665,1340 \text { and } 1584 \mathrm{~cm}^{-1}\right) \text {, amide } \mathrm{I}\left(1704 \mathrm{~cm}^{-1}\right) \text {, } \\
\text { C-H bending of proteins }\left(1028 \mathrm{~cm}^{-1}\right) \text {, lipid }\left(1460 \mathrm{~cm}^{-1}\right), \text { DNA bases }\left(1330 \mathrm{~cm}^{-1}\right) \text { [68] }\end{array}$ \\
\hline $\begin{array}{l}\text { Pseudomonas aeruginosa } \\
\text { Staphylococcus epidermidis } \\
\text { Candida albicans }\end{array}$ & $\begin{array}{l}\text { Identification of biofilm formation steps of the model microorganisms } \\
\text { Detection of pyocyanin }\left(1355 \mathrm{~cm}^{-1}\right) \\
\text { Discrimination of biofilms with using PCA } 69]\end{array}$ \\
\hline
\end{tabular}




\section{Conclusions}

Raman spectroscopy and SERS are promising techniques for identifying the chaotic composition of a biofilm at the molecular level. The discovery of spectral features specific to biofilm components and microorganisms could widen the use of the techniques in different areas such as in clinics, food and marine industries. Both techniques are also convenient to detect and characterize biofilms with their short analysis time and easy applicability relative to the other conventional techniques used in these fields. As the reports and the collaborations among the laboratories throughout the world increase, the creation of a comprehensive database for band assignments will provide new opportunities to obtain more reliable results. The combination of these techniques with other microscopic, spectroscopic, and molecular biofilm characterization techniques will also lead to a better understanding of the complex nature of biofilms.

Acknowledgments: The authors acknowledge the financial support of The Scientific and Technological Research Council of Turkey (TUBITAK Project No: 214Z129) and Yeditepe University. We also acknowledge the support of the COST action BM1401 European Network on Raman-Based Applications for Clinical Diagnostics (Raman4clinics).

Author Contributions: Seda Keleştemur and Ertug Avci wrote the paper and Mustafa Çulha advised about the content and subject flow and edited the paper.

Conflicts of Interest: The authors declare no conflict of interest.

\section{References}

1. Costerton, J.W.; Lewandowski, Z.; Caldwell, D.E.; Korber, D.R.; Lappin-Scott, H.M. Microbial biofilms. Annu. Rev. Microbiol. 1995, 49, 711-745. [CrossRef] [PubMed]

2. Vu, B.; Chen, M.; Crawford, R.J.; Ivanova, E.P. Bacterial extracellular polysaccharides involved in biofilm formation. Molecules 2009, 14, 2535-2554. [CrossRef] [PubMed]

3. Costerton, J.; Irvin, R.; Cheng, K. The bacterial Glycocalyx in nature and disease. Annu. Rev. Microbiol. 1981, 35, 299-324. [CrossRef] [PubMed]

4. Ahimou, F.; Semmens, M.J.; Haugstad, G.; Novak, P.J. Effect of protein, polysaccharide, and oxygen concentration profiles on biofilm cohesiveness. Appl. Environ. Microbiol. 2007, 73, 2905-2910. [CrossRef] [PubMed]

5. Denkhaus, E.; Meisen, S.; Telgheder, U.; Wingender, J. Chemical and physical methods for characterisation of biofilms. Microchim. Acta 2007, 158, 1-27. [CrossRef]

6. Mueller, L.N.; De Brouwer, J.F.; Almeida, J.S.; Stal, L.J.; Xavier, J.B. Analysis of a marine phototrophic biofilm by confocal laser scanning microscopy using the new image quantification software PHLIP. BMC Ecol. 2006, 6, 1. [CrossRef] [PubMed]

7. Neu, T.R.; Woelfl, S.; Lawrence, J.R. Three-dimensional differentiation of photo-autotrophic biofilm constituents by multi-channel laser scanning microscopy (single-photon and two-photon excitation). J. Microbiol. Methods 2004, 56, 161-172. [CrossRef] [PubMed]

8. Strathmann, M.; Wingender, J.; Flemming, H.-C. Application of fluorescently labelled lectins for the visualization and biochemical characterization of polysaccharides in biofilms of Pseudomonas aeruginosa. J. Microbiol. Methods 2002, 50, 237-248. [CrossRef]

9. Cortizo, M.; De Mele, M.F.L. Microstructural characteristics of thin biofilms through optical and scanning electron microscopy. World J. Microbiol. Biotechnol. 2003, 19, 805-810. [CrossRef]

10. Dynes, J.J.; Tyliszczak, T.; Araki, T.; Lawrence, J.R.; Swerhone, G.D.; Leppard, G.G.; Hitchcock, A.P. Speciation and quantitative mapping of metal species in microbial biofilms using scanning transmission X-ray microscopy. Environ. Sci. Technol. 2006, 40, 1556-1565. [CrossRef] [PubMed]

11. Hansma, H.G.; Pietrasanta, L.I.; Auerbach, I.D.; Sorenson, C.; Golan, R.; Holden, P.A. Probing biopolymers with the atomic force microscope: A review. J. Biomater. Sci. Polym. Ed. 2000, 11, 675-683. [CrossRef] [PubMed]

12. Mayer, C.; Lattner, D.; Schürks, N. 13C nuclear magnetic resonance studies on selectively labeled bacterial biofilms. J. Ind. Microbiol. Biotechnol. 2001, 26, 62-69. [CrossRef] [PubMed] 
13. Majors, P.D.; McLean, J.S.; Pinchuk, G.E.; Fredrickson, J.K.; Gorby, Y.A.; Minard, K.R.; Wind, R.A. NMR methods for in situ biofilm metabolism studies. J. Microbiol. Methods 2005, 62, 337-344. [CrossRef] [PubMed]

14. Reschiglian, P.; Zattoni, A.; Roda, B.; Michelini, E.; Roda, A. Field-flow fractionation and biotechnology. TRENDS Biotechnol. 2005, 23, 475-483. [CrossRef] [PubMed]

15. Meays, C.L.; Broersma, K.; Nordin, R.; Mazumder, A. Source tracking fecal bacteria in water: A critical review of current methods. J. Environ. Manag. 2004, 73, 71-79. [CrossRef] [PubMed]

16. Ram, R.J.; VerBerkmoes, N.C.; Thelen, M.P.; Tyson, G.W.; Baker, B.J.; Blake, R.C.; Shah, M.; Hettich, R.L.; Banfield, J.F. Community proteomics of a natural microbial biofilm. Science 2005, 308, 1915-1920. [CrossRef]

17. Lay, J.O. MALDI-TOF mass spectrometry of bacteria. Mass Spectrom. Rev. 2001, 20, 172-194. [CrossRef] [PubMed]

18. Suci, P.; Siedlecki, K.; Palmer, R.; White, D.; Geesey, G. Combined light microscopy and attenuated total reflection fourier transform infrared spectroscopy for integration of biofilm structure, distribution, and chemistry at solid-liquid interfaces. Appl. Environ. Microbiol. 1997, 63, 4600-4603. [PubMed]

19. Lohumi, S.; Kim, M.S.; Qin, J.; Cho, B.-K. Raman imaging from microscopy to macroscopy: Quality and safety control of biological materials. TrAC Trends Anal. Chem. 2017, 93, 183-198. [CrossRef]

20. Santos, I.P.; Barroso, E.M.; Schut, T.C.B.; Caspers, P.J.; van Lanschot, C.G.; Choi, D.-H.; van der Kamp, M.F.; Smits, R.W.; van Doorn, R.; Verdijk, R.M. Raman spectroscopy for cancer detection and cancer surgery guidance: Translation to the clinics. Analyst 2017, 142, 3025-3047. [CrossRef] [PubMed]

21. Rae, A.; Stosch, R.; Klapetek, P.; Walker, A.R.H.; Roy, D. State of the art Raman techniques for biological applications. Methods 2014, 68, 338-347. [CrossRef] [PubMed]

22. Efeoglu, E.; Culha, M. In situ-monitoring of biofilm formation by using surface-enhanced Raman scattering. Appl. Spectrosc. 2013, 67, 498-505. [CrossRef] [PubMed]

23. Fleischmann, M.; Hendra, P.J.; McQuillan, A.J. Raman spectra of pyridine adsorbed at a silver electrode. Chem. Phys. Lett. 1974, 26, 163-166. [CrossRef]

24. Cialla-May, D.; Zheng, X.-S.; Weber, K.; Popp, J. Recent progress in surface-enhanced Raman spectroscopy for biological and biomedical applications: From cells to clinics. Chem. Soc. Rev. 2017, 46, 3945-3961. [CrossRef] [PubMed]

25. Kahraman, M.; Mullen, E.R.; Korkmaz, A.; Wachsmann-Hogiu, S. Fundamentals and applications of SERS-based bioanalytical sensing. Nanophotonics 2017. [CrossRef]

26. Suci, P.A.; Geesey, G.G.; Tyler, B.J. Integration of Raman microscopy, differential interference contrast microscopy, and attenuated total reflection Fourier transform infrared spectroscopy to investigate chlorhexidine spatial and temporal distribution in Candida albicans biofilms. J. Microbiol. Methods 2001, 46, 193-208. [CrossRef]

27. Marcotte, L.; Barbeau, J.; Lafleur, M. Characterization of the diffusion of polyethylene glycol in Streptococcus mutans biofilms by Raman microspectroscopy. Appl. Spectrosc. 2004, 58, 1295-1301. [CrossRef] [PubMed]

28. Choo-Smith, L.-P.; Maquelin, K.; Van Vreeswijk, T.; Bruining, H.; Puppels, G.; Thi, N.N.; Kirschner, C.; Naumann, D.; Ami, D.; Villa, A. Investigating microbial (micro) colony heterogeneity by vibrational spectroscopy. Appl. Environ. Microbiol. 2001, 67, 1461-1469. [CrossRef] [PubMed]

29. Liu, H.; Xu, Q.; Huo, L.; Wei, X.; Ling, J. Chemical composition of Enterococcus faecalis in biofilm cells initiated from different physiologic states. Folia Microbiol. 2014, 59, 447-453. [CrossRef] [PubMed]

30. Sandt, C.; Smith-Palmer, T.; Pink, J.; Brennan, L.; Pink, D. Confocal Raman microspectroscopy as a tool for studying the chemical heterogeneities of biofilms in situ. J. Appl. Microbiol. 2007, 103, 1808-1820. [CrossRef] [PubMed]

31. Sandt, C.; Smith-Palmer, T.; Comeau, J.; Pink, D. Quantification of water and biomass in small colony variant PAO1 biofilms by confocal Raman microspectroscopy. Appl. Microbiol. Biotechnol. 2009, 83, 1171-1182. [CrossRef] [PubMed]

32. Samek, O.; Al-Marashi, J.; Telle, H. The potential of Raman spectroscopy for the identification of biofilm formation by Staphylococcus epidermidis. Laser Phys. Lett. 2010, 7, 378. [CrossRef]

33. Beier, B.D.; Quivey, R.G.; Berger, A.J. Raman microspectroscopy for species identification and mapping within bacterial biofilms. AMB Express 2012, 2, 35. [CrossRef] [PubMed]

34. Chen, Y.-P.; Zhang, P.; Guo, J.-S.; Fang, F.; Gao, X.; Li, C. Functional groups characteristics of EPS in biofilm growing on different carriers. Chemosphere 2013, 92, 633-638. [CrossRef] [PubMed] 
35. Ivleva, N.P.; Wagner, M.; Horn, H.; Niessner, R.; Haisch, C. Towards a nondestructive chemical characterization of biofilm matrix by Raman microscopy. Anal. Bioanal. Chem. 2009, 393, 197-206. [CrossRef] [PubMed]

36. Huang, W.E.; Ude, S.; Spiers, A.J. Pseudomonas fluorescens SBW25 biofilm and planktonic cells have differentiable Raman spectral profiles. Microbial Ecol. 2007, 53, 471-474. [CrossRef] [PubMed]

37. Sharma, G.; Prakash, A. Combined use of fourier transform infrared and Raman spectroscopy to study planktonic and biofilm cells of Cronobacter sakazakii. J. Microbiol. Biotechnol. Food Sci. 2014, 3, 310.

38. Kusić, D.; Kampe, B.; Ramoji, A.; Neugebauer, U.; Rösch, P.; Popp, J. Raman spectroscopic differentiation of planktonic bacteria and biofilms. Anal. Bioanal. Chem. 2015, 407, 6803-6813. [CrossRef] [PubMed]

39. Kusić, D.; Rösch, P.; Popp, J. Fast label-free detection of legionella spp. In biofilms by applying immunomagnetic beads and Raman spectroscopy. Syst. Appl. Microbiol. 2016, 39, 132-140. [CrossRef] [PubMed]

40. Wagner, M.; Ivleva, N.P.; Haisch, C.; Niessner, R.; Horn, H. Combined use of confocal laser scanning microscopy (CLSM) and Raman microscopy (RM): Investigations on EPS-matrix. Water Res. 2009, 43, 63-76. [CrossRef] [PubMed]

41. Andrews, J.S.; Rolfe, S.A.; Huang, W.E.; Scholes, J.D.; Banwart, S.A. Biofilm formation in environmental bacteria is influenced by different macromolecules depending on genus and species. Environ. Microbiol. 2010, 12, 2496-2507. [CrossRef] [PubMed]

42. Feng, J.; De La Fuente-Núñez, C.; Trimble, M.J.; Xu, J.; Hancock, R.E.; Lu, X. An in situ Raman spectroscopy-based microfluidic "lab-on-a-chip" platform for non-destructive and continuous characterization of Pseudomonas aeruginosa biofilms. Chem. Commun. 2015, 51, 8966-8969. [CrossRef] [PubMed]

43. Masyuko, R.N.; Lanni, E.J.; Driscoll, C.M.; Shrout, J.D.; Sweedler, J.V.; Bohn, P.W. Spatial organization of Pseudomonas aeruginosa biofilms probed by combined matrix-assisted laser desorption ionization mass spectrometry and confocal raman microscopy. Analyst 2014, 139, 5700-5708. [CrossRef] [PubMed]

44. Lanni, E.J.; Masyuko, R.N.; Driscoll, C.M.; Dunham, S.J.; Shrout, J.D.; Bohn, P.W.; Sweedler, J.V. Correlated imaging with C60-SIMS and confocal Raman microscopy: Visualization of cell-scale molecular distributions in bacterial biofilms. Anal. Chem. 2014, 86, 10885-10891. [CrossRef] [PubMed]

45. Lu, X.; Samuelson, D.R.; Rasco, B.A.; Konkel, M.E. Antimicrobial effect of diallyl sulphide on Campylobacter jejuni biofilms. J. Antimicrob. Chemother. 2012, 67, 1915-1926. [CrossRef] [PubMed]

46. Jung, G.B.; Nam, S.W.; Choi, S.; Lee, G.-J.; Park, H.-K. Evaluation of antibiotic effects on Pseudomonas aeruginosa biofilm using Raman spectroscopy and multivariate analysis. Biomed. Opt. Express 2014, 5, 3238-3251. [CrossRef] [PubMed]

47. Prabhawathi, V.; Boobalan, T.; Sivakumar, P.M.; Doble, M. Functionalized polycaprolactam as an active food package for antibiofilm activity and extended shelf life. Colloids Surf. B Biointerfaces 2014, 123, 461-468. [CrossRef] [PubMed]

48. Robert, B. Resonance Raman spectroscopy. Photosynth. Res. 2009, 101, 147-155. [CrossRef] [PubMed]

49. Pätzold, R.; Keuntje, M.; Theophile, K.; Müller, J.; Mielcarek, E.; Ngezahayo, A.; Anders-von Ahlften, A. In situ mapping of nitrifiers and anammox bacteria in microbial aggregates by means of confocal resonance Raman microscopy. J. Microbiol. Methods 2008, 72, 241-248. [CrossRef] [PubMed]

50. Kniggendorf, A.-K.; Meinhardt-Wollweber, M. Of Microparticles and bacteria identification-(resonance) Raman micro-spectroscopy as a tool for biofilm analysis. Water Res. 2011, 45, 4571-4582. [CrossRef] [PubMed]

51. Ivleva, N.P.; Wagner, M.; Horn, H.; Niessner, R.; Haisch, C. In situ surface-enhanced Raman scattering analysis of biofilm. Anal. Chem. 2008, 80, 8538-8544. [CrossRef] [PubMed]

52. Ivleva, N.P.; Wagner, M.; Horn, H.; Niessner, R.; Haisch, C. Raman microscopy and surface-enhanced Raman scattering (SERS) for in situ analysis of biofilms. J. Biophotonics 2010, 3, 548-556. [CrossRef] [PubMed]

53. O'Toole, G.; Kaplan, H.B.; Kolter, R. Biofilm formation as microbial development. Annu. Rev. Microbiol. 2000, 54, 49-79. [CrossRef] [PubMed]

54. Chao, Y.; Zhang, T. Surface-enhanced Raman scattering (SERS) revealing chemical variation during biofilm formation: From initial attachment to mature biofilm. Anal. Bioanal. Chem. 2012, 404, 1465-1475. [CrossRef] [PubMed]

55. Premasiri, W.; Moir, D.; Klempner, M.; Krieger, N.; Jones, G.; Ziegler, L. Characterization of the surface enhanced Raman scattering (SERS) of bacteria. J. Phys. Chem. B 2005, 109, 312-320. [CrossRef] [PubMed] 
56. Jarvis, R.M.; Brooker, A.; Goodacre, R. Surface-enhanced Raman scattering for the rapid discrimination of bacteria. Faraday Discuss. 2006, 132, 281-292. [CrossRef] [PubMed]

57. Çulha, M.; Adigüzel, A.; Yazici, M.M.; Kahraman, M.; Slahin, F.; Güllüce, M. Characterization of thermophilic bacteria using surface-enhanced Raman scattering. Appl. Spectrosc. 2008, 62, 1226-1232. [CrossRef] [PubMed]

58. Kahraman, M.; Yazıcı, M.M.; Şahin, F.; Çulha, M. Convective assembly of bacteria for surface-enhanced Raman scattering. Langmuir 2008, 24, 894-901. [CrossRef] [PubMed]

59. Kahraman, M.; Zamaleeva, A.I.; Fakhrullin, R.F.; Culha, M. Layer-by-layer coating of bacteria with noble metal nanoparticles for surface-enhanced Raman scattering. Anal. Bioanal. Chem. 2009, 395, 2559. [CrossRef] [PubMed]

60. Ramya, S.; George, R.; Rao, R.S.; Dayal, R. Detection of algae and bacterial biofilms formed on titanium surfaces using micro-Raman analysis. Appl. Surf. Sci. 2010, 256, 5108-5115. [CrossRef]

61. Efeoglu, E.; Culha, M. Surface-enhanced Raman scattering for biofilm characterization. Spectroscopy 2013, 28, 36-41.

62. Pearman, W.F.; Lawrence-Snyder, M.; Angel, S.M.; Decho, A.W. Surface-enhanced Raman spectroscopy for in situ measurements of signaling molecules (autoinducers) relevant to bacteria quorum sensing. Appl. Spectrosc. 2007, 61, 1295-1300. [CrossRef] [PubMed]

63. Govan, J.R.; Deretic, V. Microbial pathogenesis in cystic fibrosis: Mucoid Pseudomonas aeruginosa and Burkholderia cepacia. Microbiol. Rev. 1996, 60, 539-574. [PubMed]

64. Wu, X.; Chen, J.; Li, X.; Zhao, Y.; Zughaier, S.M. Culture-free diagnostics of Pseudomonas aeruginosa infection by Silver nanorod array based SERS from clinical sputum samples. Nanomed. Nanotechnol. Biol. Med. 2014, 10, 1863-1870. [CrossRef] [PubMed]

65. Bodelón, G.; Montes-García, V.; López-Puente, V.; Hill, E.H.; Hamon, C.; Sanz-Ortiz, M.N.; Rodal-Cedeira, S.; Costas, C.; Celiksoy, S.; Pérez-Juste, I. Detection and imaging of quorum sensing in Pseudomonas aeruginosa biofilm communities by surface-enhanced resonance Raman scattering. Nat. Mater. 2016, 15, 1203-1211. [CrossRef] [PubMed]

66. Polisetti, S.; Baig, N.F.; Morales-Soto, N.; Shrout, J.D.; Bohn, P.W. Spatial mapping of pyocyanin in Pseudomonas aeruginosa bacterial communities using surface enhanced Raman scattering. Appl. Spectrosc. 2017, 71, 215-223. [CrossRef] [PubMed]

67. Costerton, J.W.; Stewart, P.S.; Greenberg, E.P. Bacterial biofilms: A common cause of persistent infections. Science 1999, 284, 1318-1322. [CrossRef] [PubMed]

68. Chen, P.; Cui, L.; Zhang, K. Surface-enhanced Raman spectroscopy monitoring the development of dual-species biofouling on membrane surfaces. J. Membr. Sci. 2015, 473, 36-44. [CrossRef]

69. Keleştemur, S.; Çulha, M. Understanding and discrimination of biofilms of clinically relevant microorganisms using surface-enhanced Raman scattering. Appl. Spectrosc. 2017, 71, 1180-1188. [CrossRef] [PubMed] 